\title{
Equilibrium Credit Spreads and the Macroeconomy
}

\author{
João F. Gomes* $\quad$ Lukas Schmid ${ }^{\dagger}$
}

February $2009^{\ddagger}$

Preliminary: Do not quote with permission

\begin{abstract}
Credit markets play an important role in the macroeconomy and credit market data is often used to predict future macroeconomic performance. In this paper we propose a tractable general equilibrium asset pricing model with heterogeneous firms that links movements in stock and bond markets to macroeconomic activity. The model suggests that movements in risk premia in corporate bond markets are an important determinant of aggregate fluctuations. We show that movements in credit and term spreads forecast recessions by predicting future movements in corporate investment. Endogenous movements in credit markets allow our model to match the observed conditional and unconditional movements in stock market returns and credit spreads with a reasonable amount of aggregate volatility.
\end{abstract}

\footnotetext{
*The Wharton School, University of Pennsylvania

$\dagger$ The Fuqua School of Business, Duke University

${ }_{\ddagger}^{\ddagger}$ We are grateful to comments from participants at the Wharton Macro Lunch.
} 


\section{Introduction}

Much economic research has documented the role of asset market movements in both predicting and amplifying macroeconomic fluctuations. In particular, credit spreads, measured as the difference between corporate and treasury yields, have been shown to carry important information both about future movements in real activity and equity markets. Credit spreads are both large, volatile, and strongly countercyclical. A long literature has documented that credit spreads forecast both output and investment growth as well as future stock returns and stock market volatility. ${ }^{1,2}$

In this paper we address these findings in the context of a one sector general equilibrium model with heterogeneous firms that make optimal investment and financing decisions under uncertainty. By integrating corporate investment and capital structure decisions into an asset pricing model, we endogenously links movements in aggregate quantities such as investment and output to the prices of stocks and bonds. As a result movements in financial variables such as credit spreads and expected equity returns will forecast future economic activity. In our model these movements are largely driven by risk premia. Intuitively, investors incur losses on defaulted bonds in recessions, precisely when marginal utility is high giving rise to countercyclical credit spreads. In our equilibrium setting, endogenous default also increases the volatility of consumption during recessions, thereby rendering the market price of risk sharply countercyclical. As a consequence, expected returns on stocks are higher in recessions, which are naturally anticipated by movements in credit spreads.

Moreover because investors require higher compensation for default risk in bad times,

\footnotetext{
${ }^{1}$ Examples of the ability of credit spreads to forecast economic activity include studies by Bernanke, Gerler, and Gilchrist (1999), Stock and Watson (1991), Lettau and Ludvigson (2004), Gilchrist and Zakrajsek (2008), and Mueller (2008)

${ }^{2}$ Examples of the link between credit spreads and equity markets include Keim and Stambaugh (1986) and Schwert (1989).
} 
firms find it especially costly to obtain debt financing in recessions. Accordingly firms will find it harder to obtain funding for investment expenditures, thereby depressing investment and output and amplifying macroeconomic conditions. Risk premia in corporate bond markets are thus propagated into the real economy and this accounts for the predictive power of credit spreads for output and investment. Thus credit risk premium emerges as the common link between credit markets, equity markets and macroeconomic aggregates.

Quantitatively, accounting for the premia in corporate bond prices allows the model to generate sizeable credit spreads. In addition, we also show how allowing for endogenous movements in credit markets also enhances the model's ability to match the observed conditional and unconditional movements in equity markets with a reasonable amount of aggregate volatility.

Existing theoretical work has focused either on the role of asset prices in signalling a decline in future cash flows or the fact that asset prices, and in particular credit spreads, often reflect exogenous changes in credit supply. ${ }^{3}$ While all these mechanisms seem important empirically, the existing theoretical literature has mostly focused on a limited set of facts and has thus failed to provide a comprehensive explanation of the joint movements in aggregate quantities and asset prices. As a result the existing models can be viewed as offering at best a partial explanation for these co-movements and often have strongly counterfactual implications. In contrast, our model provides a unified explanation of the joint movements in macroeconomic quantities and asset prices. In particular, by adopting an equilibrium perspective it allows for a better understanding of the spillovers between asset markets and real variables, and in particular of the role of credit risk.

Methodologically, our model connects the corporate finance literature on optimal

\footnotetext{
${ }^{3}$ Recent examples include Bernanke, Gertler, and Gilchrist [1999] and Philippon [2008].
} 
capital structure and investment with the asset pricing literature on aggregate risk premia in a macroeconomic setting. While stylized, tractability makes the model a flexible environment for a quantitative analysis of the interactions between frictions at the corporate level, asset prices and macroeconomic fluctuations.

Our paper is closely related to a recent set of contributions in finance seeking to understand the level and dynamics of credit spreads in relation to macroeconomic shocks. A list of recent papers in this area includes Hackbarth, Miao, Morellec (2007), Chen, Collin Dufresne, Goldstein (2008), Chen (2008), Bhamra, Kuhn, and Strebualev (2008a). In contrast to this literature we adopt a general equilibrium perspective and study the mutual endogenous interactions between credit markets, equity markets and macroeconomic variables.

More broadly, our work adds to the literature on equilibrium asset pricing with heterogeneous firms (Gomes, Kogan, and Zhang (2003), Gourio (2006), Gala (2006)). From this point of view the novelty in our work is that we explicitly allow for deviations from the Modigliani-Miller theorems so that corporate financing decisions affect investment, and thus asset prices and output. Finally, our paper is related to recent work on corporate capital structure and financing decisions across the business cycle (Covas and Den Haan (2007), Bhamra, Kuhn and Strebulaev (2008b), Hennessy and Levy (2006)).

The paper is organized as follows. Section 2 describes our basic general equilibrium model and some of its properties, while section 3 discusses the details associated with solving it numerically. Our findings are covered in section 4 and the final section concludes. 


\section{The Model}

In this section we describe a general equilibrium complete markets model with heterogeneous firms that are financed with both debt and equity. Debt is used because of its tax benefits. Although our economy is often stylized the model presented here preserves tractability and economic intuition. Nevertheless as we will see below this economy is also suitable for detailed quantitative analysis.

\subsection{Production Sector}

The production sector of the economy is made of a continuum of firms that differ in their productivity, size and leverage among other characteristics. In characterizing the problem of firms we take the stochastic discount factor for the economy, $M$, as given. We show below how this will be determined in general equilibrium by the optimal consumption and savings decisions of households.

\subsubsection{Technology and Investment}

All firms produce the same homogeneous final good that can be used for either consumption or investment. The production function denoting the instantaneous flow of output is described by the expression:

$$
y(x, z, k)=x z k
$$

where $x$ and $z$ denote the values of aggregate and firm specific productivity, respectively. These productivities are exogenous and evolve according to first order Markov transitions denoted $Q_{x}\left(x^{\prime} \mid x\right)$ and $Q_{z}\left(z^{\prime} \mid z\right)$, respectively. Here we have used the notation $x^{\prime}$ and $z^{\prime}$ to denote the future value of the variables $x$ and $z$, respectively. The variable $k$ denotes the firm's productive capacity. This capacity is installed when the firm begins to operate and remains fixed throughout the life of the firm. 


\subsubsection{Firm Entry and Financing}

New firms can enter the market and start production if market conditions are sufficiently attractive. Entering firms draw the initial realization of the idiosyncratic shock $z$ from the invariant distribution implied by the transition $Q_{z}\left(z^{\prime} \mid z\right)$, denoted $G(z)$. This value is only observed after entry. We further assume that entering firms are not immediately productive.

Entering firms must invest to build their productive capacity, $k$. This investment can be finance with either debt or equity finance. Debt takes the form of a consol bond that pays a fixed coupon $b k$ as long as the firm is in existence and does not default on its obligations. Note that writing the coupon as $b k$ allows us to interpret $b$ as a measure of book leverage.

\subsubsection{Equity Value and Exit}

Given production and leverage the firm's operating profits are given by the expression

$$
\pi(x, z, b, k)=(x z-b) k
$$

Denote by $s$ the aggregate state of the economy, which includes the state of aggregate productivity, $x$. Taking the households pricing kernel, $M$, as given, the firm's equity value, $V(s, z, k, b)$ after entering the economy is determined through the Bellman equation

$$
V(s, z, b, k)=\max \left\{0,(1-\tau)(1-\lambda)(x z-b) k+E\left[M\left(s, s^{\prime}\right) V\left(s^{\prime}, z^{\prime}, b, k\right)\right]\right\}
$$

where $\tau$ is the marginal tax on corporate profits, adjusted for taxes on distributions and personal interest income and $\lambda$ is an indicator function that takes the value of 0 when distributions are positive and summarizes the costs of issuing equity. In the expression for the equity value we have used the notation $s^{\prime}$ to denote the future value of $s$. Finally 
note that our assumptions about the nature of cash flows implies that equity value is linear in $k$.

This Bellman equation implies that equity holders will default on their debt obligations when equity value falls to zero. This boundary condition yields a default cutoff value for the idiosyncratic shock, $\bar{z}_{d}(s, b)$, such that the firm will default whenever $z<\bar{z}_{d}(s, b)$. Formally, we define this default threshold with the condition ${ }^{4}$

$$
z_{d}(s, b)=\min \{z: V(s, z, b, k)=0\}
$$

\subsubsection{Value of Debt and Credit Spreads}

Bondholders receive the coupon $b$ when the firm does not default and will receive a fraction $1-\phi$ of the book value of the firm in case of default. Formally then, we can define the market value of debt, $B(s, z, b, k)$, in recursive form as follows

$$
B(s, z, b, k)=\left(b k+E\left[M\left(s, s^{\prime}\right) B\left(s^{\prime}, z^{\prime}, b, k\right)\right]\right) \chi_{\left\{z>\bar{z}_{d}\right\}}+(1-\phi) k\left(1-\chi_{\left\{z>z_{d}\right\}}\right)
$$

where $\chi$ is an indicator function that takes the value of 1 when $z>\bar{z}_{d}(s, b, k)$. A possible interpretation of this equation for the value of debt value is that at default the firm gets liquidated and its assets are transferred to bondholders at a discount, $1-\phi$.

Given our definition it is straightforward to define the yield $y(s, z, b, k)$ on corporate debt as

$$
y(s, z, b, k)=b / B(s, z, b, k)
$$

Moreover we can construct measures of the credit spread for this economy by comparing this quantity with the yield on a riskless bond of identical maturity. Formally:

$$
c s(s, z, b, k)=y(s, z, b, k)-y_{f}(s, z, b, k)
$$

where $y_{f}(s, z, b, k)$ is the yield on a bond of identical characteristics but assuming no default occurs (and thus similar to a AAA rated bond).

\footnotetext{
${ }^{4}$ Linearity of the value function implies that the cut-off is independent of $k$.
} 


\subsubsection{Entry and Optimal Capital Structure}

Given the expression for equity and debt value, the expected value of entry, for any level of leverage $b$, in aggregate state $s$ is given by the expression:

$$
\int V(s, z, b, k)+B(s, z, b, k) d G(z)
$$

Upon entering the firm invests to build up the required productive capacity, $k$, at unit cost $e$. Thus, in our framework a minimum productive capacity is required to operate the firm, while the cost of installation varies across firms. These installation costs are randomly drawn from a continuous distribution $H(e)$. As we will see below this implies that only a subset of potential entrants actually begins production in a given period.

The firm finances these purchases of capital using an optimal mix of debt and equity. This optimal capital structure can be found by optimizing the expected firm value with respect to the instantaneous level of coupon payments, $b$. Formally then the optimal ex-ante value of the firm (i.e. debt plus equity) $A_{0}(s)$ is given by the expression:

$$
A_{0}(s, k)=\max _{b \geq 0}\left\{\int V(s, z, b, k)+B(s, z, b, k) d G(z)\right\}
$$

It follows that firms will enter the economy if and only if the setup cost $e k$ is less or equal the ex ante firm value $A_{0}(s, k)$. Formally, entry occurs whenever

$$
e \leq \bar{e}(s)=A_{0}(s, k) / k
$$

Note that because the value of the firm is homogenous of degree 1 in $k$ the cutoff level of installation costs, $e$, does not depend on the scale of production.

To summarize the solution of the problem of every firm is characterized by

- the entry cutoff, $\bar{e}(s)$, implied by condition (10),

- An optimal leverage choice, $b=\bar{b}(s)$ implied by (9), and

- An optimal default cutoff, $z=z_{d}(s, b)$, implied by (4). 
It is clear from these definitions however, that all of these decisions depend on the aggregate state of the economy, which needs to be in general equilibrium.

\subsection{Aggregation}

Given the optimal behavior for individual firms described above we can construct aggregate quantities in this economy. First however let us define $\mu(b, z ; x)$ as the crosssectional distribution of firms over leverage and idiosyncratic shocks. Note that this distribution will in general vary over time according to the state of aggregate productivity $x$. However there is no cross-sectional variation in productive capacity since this is constant across firms.

We can now construct aggregate output as follows:

$$
\mathbf{Y}(x, \mu)=\int_{z_{d(s, b)}}^{\infty} x z k d \mu
$$

Similarly aggregate investment equals the sum of the setup costs for entering firms:

$$
\mathbf{I}(x, \mu)=\int_{0}^{\bar{e}(s)} k d H(e) d \mu
$$

Finally we can define aggregate market value of corporate equity and debt respectively with the expressions:

$$
\mathbf{V}(x, \mu)=\int_{z_{d(s, b)}}^{\infty} V(s, z, k, b) d \mu
$$

and

$$
\mathbf{B}(x, \mu)=\int_{z_{d(s, b)}}^{\infty} B(s, z, k, b) d \mu
$$

Similar aggregates can also be constructed for the total amount of resources spent in bankruptcy procedures as well as the accumulated value of tax revenues to the government.

It follows from the definitions for the aggregate quantities that we can fully characterize the aggregate state of our economy $s$, with the pair $(x, \mu)$. Intuitively aggregate 
quantities and prices will depend both on the aggregate state of productivity and profits but also on the cross-sectional variation in firm productivities and balance sheet positions.

\subsection{Households}

The economy is populated by identical competitive households, who derive utility from the consumption flow of the single consumption good, $C_{t}$. The household maximizes the discounted value of future utility flows, defined through the Epstein-Zin (1991) and Weil (1990) recursive function:

$$
U_{t}=\left\{(1-\beta) u\left(C_{t}\right)^{1-1 / \sigma}+\beta \mathrm{E}_{t}\left[U_{t+1}^{1-\gamma}\right]^{1 / \kappa}\right\}^{1 /(1-1 / \sigma)} .
$$

The parameter $\beta \in(0,1)$ is the household's subjective discount factor and $\gamma>0$ is the coefficient of relative risk aversion. The parameter $\sigma \geq 0$ denotes the elasticity of intertemporal substitution and $\kappa=(1-\gamma) /(1-1 / \sigma)$.

We assume that there exists a complete set of financial markets, including an instantaneously riskless bond in zero net supply that earns a rate of interest $r_{t}$. There are no frictions and no constraints on short sales or borrowing. Accordingly there is a unique equilibrium pricing kernel, denoted $M_{t, t+s}$ which determines prices of all financial assets.

The representative household maximizes the expected utility of consumption (15), taking the prices of financial assets as given. In a complete financial market, the budget constraint is given by:

$$
E_{t}\left[\int_{0}^{\infty} M_{t, t+s} C_{t+s} d s\right] \leq W_{t}
$$

where $W_{t}$ denotes accumulated household wealth. This measure includes both the market value of equity and debt but also the present value of all tax rebates and bankruptcy costs. $^{5}$ Thus we assume that bankruptcy costs associated with the liquidation of cor-

\footnotetext{
${ }^{5}$ We are assuming that households invest directly in the aggregate stock and bond market portfolio.
} 
porations accrue to specialized firms (e.g. law practices) which are also owned by the representative agent.

Formally the equilibrium pricing kernel is then given by the expression

$$
M_{t, t+1}=\left[\beta\left(\frac{C_{t+1}}{C_{t}}\right)^{-1 / \sigma} R_{W, t+1}^{1-1 / \kappa}\right]^{\kappa} .
$$

where we have defined the expression

$$
R_{W, t+1}=\frac{W_{t+1}+C_{t+1}}{W_{t}}
$$

as the return on total household wealth.

As is well known, the absence of arbitrage implies that all gross asset returns in this economy will satisfy:

$$
\mathrm{E}_{t}\left[M_{t+1} R_{i, t+1}\right]=1
$$

for all assets $i$.

\subsection{Equilibrium}

As we have seen given the stochastic discount factor firm's behavior determines aggregate investment and output as well as household wealth. On the other hand household behavior determines the equilibrium stochastic discount factor, given the level of wealth. A competitive equilibrium can then be constructed by imposing that:

$$
C_{t}=C(x, \mu)=\mathbf{Y}(x, \mu)-\mathbf{I}(x, \mu)
$$

so that the stochastic discount factor used by firms corresponds to that implied by optimal household behavior. Moreover, because tax revenues and bankruptcy costs are redistributed to the representative household, Walras' law implies that equilibrium in the capital market also holds as long as equation (19) is satisfied. 


\section{Computation}

This section describes our approach to solve the model in section 2. Although the model is fairly stylized the competitive equilibrium is a complex object and its computation requires the use of numerical methods. Below we explain our choices for the key parameters in the model and offer an overview of the numerical algorithm that we employ.

\subsection{Parameter Choices}

Table 1 reports the parameters that we use for our calibration. As usual we set the preference parameters $\beta, \gamma$ and $\sigma$ to generate the right levels for the risk free rate and the equity premium in the economy. Their values are also very similar to those used in most recent quantitative studies that rely on time non-separable preferences and persistent shocks to aggregate growth (e.g. Bansal and Yaron (2004)).

The stochastic behavior of the (log) aggregate and idiosyncratic productivity shocks is restricted to follow a first order autoregressive process with normal innovations. Specifically we assume that

$$
\begin{gathered}
\log \left(x_{t}\right)=\rho_{x} \log \left(x_{t-1}\right)+\sigma_{x} v_{x t}, \\
\log \left(z_{t}\right)=\rho_{z} \log \left(z_{t-1}\right)+\sigma_{z} v_{z t},
\end{gathered}
$$

where both $v_{x t}$ and $v_{z t}$ are independently and identically distributed shocks drawn from a standard normal distribution. Our assumptions combined with a linear technology imply that the aggregate economy experiences stochastic and persistent variation in its growth rate over time through fluctuations in aggregate productivity, $x_{t}$.

To pin down the volatility and persistence of the aggregate productivity process we require that our model matches the volatility and persistence of output growth in the data. This implies that $\rho_{x}=0.9995$ and $\sigma_{x}=0.004$. The parameters for idiosyncratic shocks determine the amount of cross-sectional variation in firm heterogeneity. Since 
we are especially concerned with the role of leverage and credit spreads in our economy we set these parameters to match the unconditional means of both of these variables. Thus we choose the value of $\rho_{z}=0.97$ and $\sigma_{z}=0.15$

Beyond these choices we only need to determine the value of the marginal corporate tax rate, $\tau$ and bankruptcy and issuance costs, $\phi$ and $\lambda$, respectively. In line with previous studies we assume that the marginal tax rate equals 0.2 a value that reflects both the effects of direct corporate income taxes and those of individual income taxes on distributions and interest. For an estimate of bankruptcy costs we turn to Werner (1977) who suggests that a value of about 0.25 reflects both the direct and indirect costs associated with this process. Finally we use the value of $4 \%$ to denote the marginal cost of issue equity, an estimate that is similar to that used in Gomes (2001) and estimated in Hennessy and Whited (2006).

\subsection{Computation Details}

We use numerical dynamic programming to solve the model. However the solution is complicated by the endogeneity of the pricing kernel, which embodies the equilibrium market clearing conditions, and by the dependence of the aggregate quantities on the cross-sectional distribution, $\mu$, which is a high-dimensional object.

Our solution algorithm exploits two techniques to overcome these obstacles. First, as in Kahn and Thomas (2006), we renormalize the value functions for debt and equity to express them in units of marginal utility which is computationally more convenient. Next, following Krusell and Smith (1998), the cross-sectional distribution $\mu$ is approximated by a low-dimensional state variable that summarizes the relevant information in $\mu$.

The expression for the pricing kernel 17 guides both our choice of the approximate 
state space and renormalizations. To that end, we define the function:

$$
p(C, W)=C^{-\frac{\kappa}{\sigma}} W^{\kappa-1}
$$

and rewrite the expression for the (normalized) equity value of the firm as

$$
\begin{aligned}
\hat{V}(s, z, b) & =V(s, z, b, k) p(C, W) / k \\
& =V(s, z, b, k) C^{-\frac{\kappa}{\sigma}} W^{\kappa-1} k^{-1}
\end{aligned}
$$

In an analogous way we can define $\hat{B}(s, z, b)$ as the normalized market value of debt.

In the next step, we approximate the high-dimensional state space $s=(x, \mu)$ by $\hat{s} \equiv(x, W)$. In other words, aggregate household wealth $W$ captures all the relevant information about aggregate quantities contained in the cross-sectional distribution $\mu$.

We can then write

$$
\begin{aligned}
\hat{\hat{V}}(x, W, z, b)= & \hat{V}(\hat{s}, z, b) \\
= & \max \left\{0,(1-\tau)(1-\lambda)(x z-b) \hat{C}(x, W)^{-\frac{\kappa}{\sigma}} W^{\kappa-1}\right. \\
& \left.+E\left[\beta^{\kappa}\left(\frac{W^{\prime}+\hat{C}\left(x^{\prime}, W^{\prime}\right)}{\hat{C}(x, W)}\right)^{\kappa-1} \hat{\hat{V}}\left(x^{\prime}, W^{\prime}, z^{\prime}, b\right)\right]\right\}
\end{aligned}
$$

where $\hat{C}(x, W)=C(\hat{s})$ in our approximate state space. $\hat{\hat{B}}(x, W, z, b)$ is also defined analogously.

Our numerical strategy is based on numerically iterating on the functional equations $\hat{\hat{V}}$ and $\hat{\hat{B}}$. To that end, we parameterize the consumption function $\hat{C}$ and the law of motion for aggregate wealth $W^{\prime}=\Gamma(x, W)$ as log linear functions of the aggregate state, $x$ and $W$. More explicitly, we set

$$
\begin{aligned}
\log C & =\alpha_{0}+\alpha_{1} \log x+\alpha_{2} \log W \\
\log W^{\prime} & =\eta_{0}+\eta_{1} \log x+\eta_{2} \log W
\end{aligned}
$$

for some coefficient vectors $\alpha$ and $\eta$. Following Krusell and Smith (1998), we guess an initial set of coefficients for these rules, and find the equilibrium rules by means of simulation. More precisely, we use the following procedure: 
- Discretize the state space by choosing discrete grids for $b$ and $W$, and the shocks $x$ and $z$. Because the stochastic processes in our calibration are highly persistent, we discretize the shocks using the procedure detailed in Rouwenhorst (1995).

- Guess initial vectors $\alpha^{0}$ and $\eta^{0}$

- Using these guesses iterate on the functional equations for $\hat{\hat{V}}$ and $\hat{\hat{B}}$. This yields the optimal decision rules for investment, default and optimal capital structure.

- Simulate the optimal decisions rules and compute the implied general equilibrium allocations for $C$ and $W$.

- Use the implied time series for $x, C$ and $W$ to update the approximate log linear rules for $C$ and $W^{\prime}$ and check the goodness of fit.

- Iterate until convergence.

\section{Findings}

We are now ready to describe our quantitative findings. We begin by summarizing the basic properties of the model as summarized by the unconditional means and volatilities in aggregate quantities and asset prices. We then examine the model's implications for the behavior of financial variables over the business cycle and compare those with the available empirical evidence. Finally we investigate the role of credit spreads in predicting future movements in both macro quantities and in equity markets.

To construct the statistics reported below we solve the model by numerical dynamic programming as detailed in 3. We then simulate the implied equilibrium policies at monthly frequency to construct 1000 independent panels of 57 years each. Macroeconomic data is aggregated at the quarterly frequency to match the available data. Unless 
otherwise noted we always report the relevant empirical moments for the sample period between 1951 and 2007.

\subsection{Basic Properties}

The first panel in Table 2 reports the volatility of the key macroeconomic variables as well as the share of investment in GDP. We can see that our parameter choices imply a very close match between the model and the data along these dimensions. Not only is the share of investment (and consumption) plausible but both variables also seem to exhibit as much variability as in the actual data.

The lower panel in Table 2 documents the implied properties of the model for the unconditional means and volatilities of the risk free rate and the equity premium. As we can see, our model does a very job in replicating these difficult objects. Both the level of the risk free rate and the equity premium are very close to those observed in the data, and this match does not require the very large movements in the risk free rate often associated with habit preferences.

While Bansal and Yaron (2004) have shown that accounting for long run movements in consumption and dividends in conjunction with preferences for a early resolution of uncertainty delivers realistic risk premia in an endowment economy setting, this has proved harder to implement in general equilibrium production economies (Kaltenbrunner and Lochstoer (2008), Campanale, Castro and Clementi (2008)). This is because in a production economy, general equilibrium restrictions usually tie dividends very closely to consumption, while empirically, dividends are much more volatile than consumption.

By endogenizing financial leverage however, our model breaks the tight link between dividends and consumption and renders dividends an order of magnitude more volatile. This allows us to generate a realistic amount of stock market volatility which is crucial in matching the aggregate equity premia. Importantly however, the model also produces 
very slow moving patterns in leverage (Lemmon, Roberts and Zender (2008)) and the long run movements in aggregate dividends similar to those in Bansal and Yaron (2004).

\subsection{Credit Market Statistics}

Table 3 shows the basic properties of the key credit market statistics as well as its empirical counterparts. Unlike the previous table however which was focused on aggregate variables, the statistics reported in Table 3 are based on the average properties of the cross-sectional distribution of firms.

The Table shows that our parameter choices imply that the model matches almost exactly the cross-sectional average market leverage - usually constructed by dividing the ratio of book leverage by the value of market equity plus book leverage. Moreover the model also yields a realistic level of credit defaults in our model, at about $1.48 \%$ per year. More challenging, but equally successful, is the comparison with the average credit spread in the data.

The low default rate and the considerable tax benefit to debt are often interpreted as suggesting that firms should optimally choose leverage ratios much higher than those observed in the data. In our model however, firms anticipate having to issue equity to able to cover the coupon expenses in times of low profits. Since these issues are also costly, firms will optimally choose lower leverage ratios ex ante.

As in recent work by Bhamra et al (2008) and Chen (2008), macroeconomic fluctuations are crucial for generating a realistic average credit spread in the model. In our model however, these fluctuations are driven by the endogenous interplay between investment and the dynamics of the firm distribution and firms' financing decisions. Firms entering the economy in booms will anticipate high profits in the future, which they optimally shield from taxes by tilting their capital structure towards debt financing. This renders book leverage procyclical in our model. When the economy slips into 
a recession however, default rates increase and incumbents' bonds quickly loose value while credit spreads increase.

\subsection{Investment and Finance over the Business Cycle}

Table 4 documents the cyclical behavior of several investment and financing variables by reporting their cross-correlations with GDP. The table shows that all variables have the correct cyclical behavior in our model although the implied correlations are usually too high. Because our model has only one source of aggregate uncertainty the innovations in aggregate GDP growth are completely tied to those in aggregate productivity. As a result most of these relations can be understood by examining the effects of aggregate productivity of the various variables.

Intuitively the persistence in the aggregate shocks renders implies a strongly procyclical behavior in aggregate investment as new firms enter the market and build up productive capacity in anticipation of higher future profits. As a result the market value of firms (and especially of equity) is also strongly pro-cyclical implying a countercyclical pattern in market leverage.

Also intuitive is the behavior of both default rates and credit spreads which are strongly countercyclical since default is becomes less attractive when profits are temporarily high. As a result of this improvement in credit market conditions which leads book leverage will rise. This is because new entrants will choose a typically higher level of debt thus raising average leverage in the economy.

As in the data, firms are more likely to issue equity during good times in the model. Two effects are at work here, and they work in opposite directions. In the model firms issue equity at entry to finance investment in productive capacity and later on they need to secure additional funds in times of low profits in order to cover coupon expenses. This later effect leads to countercyclical issues but quantitatively it is not 
very strong. Anticipating that issuing equity is particularly costly in bad times, firms shift their initial capital structure towards equity when entering the economy, which is more likely to happen in times of high profits, thus rendering aggregate equity issuances procyclical.

\subsection{Credit Spreads and Predictability in Equity Markets}

We now turn to the role of credit markets, and in particular of credit spreads, in forecasting movements in equity markets. Table 7 shows the results of regressing the $\mathrm{k}$ period ahead return on the aggregate stock market, on the credit spread at time t. The tables shows that credit spreads in our model are able to predict future equity returns at horizons ranging between 1 quarter and 1 year ahead. For comparison we also report the recent empirical findings in Fama and French (2002).

As we can see from this table, although short horizon predictability is not statistically very significant it rises in importance with the horizon until it becomes fairly strong at a 1 year horizon. Thus, in the model as in the data, an increase in credit spreads anticipates a future rise in equity returns.

An explanation for this finding is suggested by the results in Table 8. Here we used the value of the credit spread at time $t$ to forecast the volatility in the aggregate stock market over the next quarter. We also report the findings in Schwert (1989) who performs a similar exercise in the data. For completeness we also include the result of using market leverage in the forecasting regression used by Schwert (1989).

Our results show that, as in the data, a rise in credit spreads forecasts an increase in stock market volatility. This evidence seems to confirms that movement in credit spreads are associated with changes in risk premia. Intuitively this occurs because investors incur larger losses on defaulted bonds in recessions, precisely when marginal utility is high giving rise to countercyclical credit spreads. 
In our equilibrium setting then, endogenous default increases the volatility of consumption during recessions, thereby rendering the market price of risk sharply countercyclical. As a consequence, expected returns on stocks are higher in recessions, and this is naturally anticipated by movements in credit spreads.

\subsection{Credit Spreads and Business Cycle Predictability}

Finally tables 5 and 6 show the results of regressing the k period ahead growth in $(\log )$ output and investment, respectively, on the value weighted aggregate credit spread at time t.

These tables show that credit spreads in our model are able to forecast movements in both aggregate output and investment at horizons ranging between 1 quarter and 1 year. This finding is then consistent with much empirical evidence about the forecasting ability of credit spreads and document recently in Mueller (2008), Gilchrist et al (2008) and Lettau and Ludvigson (2004). In both the data and the model the forecasts are both statistically and economically meaningful. Moreover the estimated coefficients on the simulated panels are of very similar magnitudes to those found in recent empirical studies.

The intuition for these results follows from the fact that the cyclical nature of consumption implies that investors will require higher compensation for default risk in bad times. As a consequence firms find it especially costly to obtain debt financing during recessions. In our model, this makes it difficult for the young (new) firms to obtain funding for investment expenditures and depresses aggregate investment and output for a number of quarters thereafter. Risk premia in corporate bond markets are thus propagated into the real economy and this accounts for the predictive power of credit spreads for output and investment. Moreover these endogenous movements in risk premia play a key role in amplifying underlying macroeconomic conditions. Thus credit risk premium 
emerges as the common link between credit markets, equity markets and macroeconomic aggregates.

To summarize then our findings suggest that, as in earlier studies, accounting for the premia in corporate bond prices allows the model to generate sizeable credit spreads. In addition however, we also show how, in general equilibrium, allowing for endogenous movements in credit markets enhances the model's ability to match the observed conditional and unconditional movements in equity markets and macroeconomic aggregates.

While a long theoretical literature has demonstrated that financial frictions have the potential to deliver a powerful amplification mechanism for macroeconomic shocks, our mechanism here is distinct. Classical papers in this literature (e.g. Kyotaki and Moore (1997), Bernanke, Gertler, Gilchrist (1999), Cooley, Marimon and Quadrini (2004) and others) often emphasize the agency problems arising between investors and small entrepreneurial firms and focus on how changes in aggregate economic conditions exacerbate these frictions. In contrast, in our model shocks are amplified through endogenous movements in credit risk premia that affects all corporations equally. As a result our model offers a more plausible mechanism for the role of financial markets in the propagation of the underlying shocks.

\section{Conclusion}

In this paper we propose a tractable general equilibrium asset pricing model with heterogeneous firms that links movements in stock and bond markets to macroeconomic activity. The model endogenously links movements in aggregate quantities such as investment and output to the prices of stocks and bonds. As a result movements in financial variables such as credit spreads and expected equity returns will forecast future economic activity. In our model these movements are largely driven by risk premia. 
In our equilibrium setting, endogenous default increases the volatility of consumption during recessions, thereby rendering the market price of risk sharply countercyclical. As a consequence, expected returns on stocks are higher in recessions, which are naturally anticipated by movements in credit spreads. Endogenous movements in credit markets allow our model to match the observed conditional and unconditional movements in stock market returns and credit spreads with a reasonable amount of aggregate volatility. 


\section{References}

Alvarez, Fernando and Urban Jermann, 2000, Efficiency, Equilibrium and Asset Pricing with Risk of Default, Econometrica, 775-797

Alvarez, Fernando and Urban Jermann, 2001, Quantitative Asset Pricing Implications of Endogenous Solvency Constraints, Review of Financial Studies, 1117-1152

Bansal, Ravi and Amir Yaron, 2004, Risks for the Long Run: A Potential Resolution of Asset Pricing Puzzles, Journal of Finance 59, 1639-1672

Bhamra, Harjoat, Lars-Alexander Kühn and Ilya Strebulaev, 2008, The Levered Equity Risk Premium and Credit Spreads: A Unified Framework, working paper, Stanford University

Bhamra, Harjoat, Lars-Alexander Kühn and Ilya Strebulaev, 2008, The Aggregate Dynamics of Capital Structure and Macroeconomic Risk, working paper, Stanford University

Bernanke, Ben, Mark Gertler, and Simon Gilchrist, 1999, The Financial Accelerator in a Quantitative Business Cycle Framework, in Handbook of Macroeconomics, Edited by Michael Woodford and John Taylor, North Holland.

Campanale, Claudio, Rui Castro and Gian Luca Clementi, 2008, Asset Pricing in a Production Economy with Chew-Dekel Preferences, working paper, New York University

Chang, Ganlin and Suresh Sundaresan, 2005, Asset Prices and Default-Free Term Structure in an Equilibrium Model of Default, Journal of Business, 78, 1215-1266

Chen, Long, Pierre Collin-Dufresne and Robert Goldstein, 2008, On the Relation between Credit Spread Puzzles and the Equity Premium Puzzle, forthcoming Review 
of Financial Studies

Chen, Hui, 2008, Macroeconomic Conditions and the Puzzles of Credit Spreads and Capital Structure, working paper, MIT

Cooley, Thomas, Ramon Marimon and Vincenzo Quadrini, 2004, Aggregate Consequences of Aggregate Contract Enforceability, Journal of Political Economy, 112, 817-847

Cooper, Ilan and Richard Priestley, 2004, Stock Return Predictability in a Production Economy, working paper, BI School Oslo

Covas, Francisco and Wouter Den Haan, 2007, The Role of Debt and Equity over the Business Cycle, working paper, University of Amsterdam

Fama, Eugene F., and Kenneth R. French, 1992, Business Conditions and Expected Returns on Stocks and Bonds, Journal of Financial Economics, 25, 23-49.

Fama, Eugene F., and Kenneth R. French, 1993, Common Risk Factors in the Returns on Stocks and Bonds, Journal of Financial Economics, 33, 3-56.

Gala, Vito, 2007, Investment and Returns, working paper, London Business School

Gilchrist, Simon and Charles Himmelberg, 1998, Investment: Fundamentals and Finance, in NBER Macroeconommics Annual, Ben Bernanke and Julio Rotemberg eds, MIT Press

Gilchrist, Simon, Vladimir Yankov and Egon Zakrajsek, 2008, Credit Market Shocks and Economic Fluctuations: Evidence from Corporate Bond and Stock Markets, working paper, Boston University

Gomes, João F., 2001, Financing Investment, American Economic Review, 90, 5, 12631285. 
Gomes, João F., Leonid Kogan, and Motohiro Yogo, 2008, Durability of Output and Expected Stock Returns, working paper, University of Pennsylvania

Gomes, João F., Leonid Kogan, and Lu Zhang, 2003, Equilibrium Cross-Section of Returns, Journal of Political Economy, 111, 693-731.

Gomes, João F., Amir Yaron, and Lu Zhang, 2006, Asset Pricing Implications of Firm's Financing Constraints, Review of Financial Studies, 19, 1321-1356.

Gomes, João F., and Lukas Schmid, 2008, Levered Returns, forthcoming Journal of Finance

Gourio, Francois, 2007, Labor Leverage, Firms Heterogeneous Sensitivities to the Business Cycle, and the Cross-Section of Returns, working paper, Boston University

Hackbarth, Dirk, Jianjun Miao and Erwan Morellec, 2006, Capital Structure, Credit Risk and Macroeconomic Conditions, Journal of Financial Economics, 82, 519-550

Hennessy, Christopher, and Amnon Levy, 2007, Why does Capital Structure Choice Vary with Macroeconomic Conditions? , Journal of Monetary Economics, 54, $1545-1564$

Hennessy, Christopher, and Toni Whited, 2005, Debt Dynamics Journal of Finance, $60,1129-1165$

Jermann, Urban and Vivien Yue, 2007, Interest Rate Swaps and Corporate Default, working paper, University of Pennsylvania.

Kaltenbrunner, Georg and Kars Lochstoer, 2008, Long Run Risk through Consumption Smoothing, working paper, Columbia University

Kiyotaki, Nobu and John Moore, 1997, Credit Cycles, Journal of Political Economy, $105,211-248$ 
Keim, Donald and Robert Stambaugh, 1986, Predicting Returns in the Stock and Bond Markets, Journal of Financial Economics, 17, 357-390

Khan, Aubhik, and Julia Thomas, 2003, Nonconvex Factor Adjustments in Equilibrium Business Cycle Models: Do Nonlinearities Matter? Journal of Monetary Economics, 50, 331-360

Krusell, Per and Anthony Smith, 1998, Income and Wealth Heterogeneity in the Macroeconomy, Journal of Political Economy, 106, 867-896

Kühn, Lars-Alexander, 2008, Asset Pricing Implications of Real Investment Commitment, working paper, Carnegie Mellon University

Leland, Hayne, 1994, Corporate Debt Value, Bond Covenants, and Optimal Capital Structure, Journal of Finance, 49, 1213-1252

Lettau, Martin and Sydney Ludvigson, 2002, Time-Varying Risk Premia and the Cost of Capital: An Alternative Implication of the Q-Theory of Investment, Journal of Monetary Economics, 49, 31-66

Müller, Philippe, 2008, Credit Spreads and Real Activity, working paper, London School of Economics

Philippon, Thomas, 2008, The Bond Market's Q, forthcoming, Quarterly Journal of Economics

Schwert, William, 1989, Why does Stock Market Volatility Change over Time?, Journal of Finance, 44, 1115-1153

Stock, James and Mark Watson, 1999, Business Cycle Fluctuations in U.S. Macroeconomic Time Series, Handbook of Macroeconomics 
Strebulaev, Ilya, 2007, Do Tests of Capital Structure mean what they say?,Journal of Finance, 62, 1747-1788

Sundaresan, Suresh, and Neng Wang, 2006, Dynamic Investment, Capital Structure, and Debt Overhang, working paper, Columbia University 


\section{Table 1: Calibration}

\begin{tabular}{|c|c|}
\hline \multicolumn{2}{|c|}{ Parameter Values } \\
\hline$\beta$ & 0.98 \\
$\sigma$ & 10 \\
$\tau$ & 2 \\
$\lambda$ & 0.2 \\
$\phi$ & 0.04 \\
$\rho_{x}$ & 0.25 \\
$\sigma_{x}$ & 0.004 \\
$\rho_{z}$ & 0.97 \\
$\sigma_{z}$ & 0.15 \\
\hline
\end{tabular}

This table reports parameter choices for our model. The model is calibrated at monthly frequency to match data both at the macro level and in the cross-section. The implied moments are reported in table 2 . 


\section{Table 2: Aggregate Moments}

\begin{tabular}{|l||l||l|}
\hline Variable & Data & Model \\
\hline \hline \multicolumn{2}{|l|}{ Macro Moments } \\
\hline $\begin{array}{l}\sigma\left[\Delta_{C}\right] \\
\frac{\sigma\left[\Delta_{C}\right]}{\sigma\left[\Delta_{Y}\right]}\end{array}$ & 2.22 & 2.09 \\
$\frac{\sigma\left[\Delta_{I}\right]}{\sigma\left[\Delta_{Y}\right]}$ & 2.56 & 0.44 \\
$\frac{I}{Y}$ & 0.19 & 0.21 \\
\hline Asset Pricing Moments \\
\hline$E\left[r^{f}\right]$ & 1.62 & 1.31 \\
$\sigma\left[r^{f}\right]$ & 2.25 & 1.79 \\
$E\left[r^{e}-r^{f}\right]$ & 6.18 & 5.92 \\
$\sigma\left[r^{e}\right]$ & 16.54 & 15.26 \\
\hline
\end{tabular}

This table reports unconditional sample first and second moments generated from the simulated data of some key variables of the model. The model is simulated 1000 times over 57 years. All data are annualized. The return on equity refers to the value weighted aggregate stock market return. The corresponding parameter values used in the simulation are reported in table 2 . The data are taken from Gomes, Kogan and Yogo (2008).

Table 3: Credit Market Statistics

\begin{tabular}{|l||l||l|}
\hline Variable & Data & Model \\
\hline \hline Default rate & 1.48 & 1.41 \\
Credit Spread (10yr BAA-AAA) & 101 & 97 \\
Market Leverage & 0.35 & 0.36 \\
\hline
\end{tabular}

This table reports statistics related to credit markets and firms' capital structures. The model is simulated 1000 times over 57 years. All data are annualized.The default rate is from Jermann and Yue (2007), the credit spread and leverage ratio is from Chen, Collin-Dufresne and Goldstein (2008). 


\section{Table 4: Financing Over Business Cycle}

\begin{tabular}{|l||l||l|}
\hline Correlation w/ GDP & Data & Model \\
\hline \hline Investment & 0.37 & 0.72 \\
Book leverage & 0.13 & 0.87 \\
Market leverage & -0.11 & -0.69 \\
Equity Issuance & 0.32 & 0.31 \\
Default rate & -0.33 & -0.91 \\
Credit Spread & -0.36 & -0.77 \\
\hline
\end{tabular}

This table reports business cycle properties of key financial variables in the model. The model is simulated 1000 times over 57 years. All data are annualized. The data are from Covas and den Haan (2008).

\section{Table 5: Forecasting Output Growth}

\begin{tabular}{|l||l|l|l|}
\hline$\Delta Y_{t, t+k}$ & \multicolumn{4}{l|}{ Actual Data } \\
\hline Horizon $k$ & 1 quarter & 2 quarter & 1 year \\
\hline \hline$C S_{t}$ & -1.37 & -1.47 & -1.47 \\
& $(2.32)$ & $(2.77)$ & $(2.94)$ \\
\hline \hline$\Delta Y_{t, t+k}$ & Simulated Data & \\
\hline Horizon $k$ & 1 quarter & 2 quarter & 1 year \\
\hline \hline$C S_{t}$ & -1.71 & -2.14 & -2.31 \\
& $(3.72)$ & $(4.37)$ & $(5.5)$ \\
\hline
\end{tabular}

This table reports regressions corresponding to Mueller (2009), table I. It regresses the k period ahead output $\log$ growth $\Delta Y_{t, t+k}=\log Y_{t+k}-\log Y_{t}$ on the value weighted aggregate credit spread at time t, $C S_{t}$. T-statistics are reported in parentheses below. These numbers are obtained by averaging the results from simulating the economy 1000 times over 57 years. The standard errors are corrected using Newey-West with 8 lags. 
Table 6: Forecasting Investment Growth

\begin{tabular}{|l||l|l|l|}
\hline \multicolumn{1}{|l||}{$\Delta I_{t, t+k}$} & \multicolumn{3}{l|}{ Actual Data } \\
\hline Horizon $k$ & 1 quarter & 2 quarter & 1 year \\
\hline \hline$C S_{t}$ & -0.02 & -0.03 & -0.03 \\
& $(-3.59)$ & $(-2.72)$ & $(-1.64)$ \\
\hline \hline$\Delta I_{t, t+k}$ & \multicolumn{1}{|l|}{ Simulated Data } \\
\hline Horizon $k$ & 1 quarter & 2 quarter & 1 year \\
\hline \hline$C S_{t}$ & -0.04 & -0.04 & -0.06 \\
& $(-2.28)$ & $(-2.51)$ & $(-2.16)$ \\
\hline
\end{tabular}

This table reports regressions corresponding to Lettau and Ludvigson (2002), table II. It regresses the $\mathrm{k}$ period ahead investment growth $\Delta I_{t, t+k}=I_{t+k}-I_{t}$ on the value weighted aggregate credit spread at time t, $C S_{t}$. T-statistics are reported in parentheses below. These numbers are obtained by averaging the results from simulating the economy 1000 times over 57 years. The standard errors are corrected using Newey-West with 8 lags. 
Table 7: Forecasting Stock Returns

\begin{tabular}{|l||l|l|l|}
\hline \multicolumn{1}{|l||}{$\mathrm{R}_{t, t+k}$} & \multicolumn{3}{l|}{ Actual Data } \\
\hline Horizon $k$ & 1 month & 1 quarter & 1 year \\
\hline \hline$C S_{t}$ & $\begin{array}{l}0.52 \\
(1.43)\end{array}$ & $\begin{array}{l}2.18 \\
(1.61)\end{array}$ & $\begin{array}{l}10.98 \\
(2.12)\end{array}$ \\
\hline \hline $\mathrm{R}_{t, t+k}$ & Simulated Data & \\
\hline Horizon $k$ & 1 month & 1 quarter & 1 year \\
\hline \hline$C S_{t}$ & 0.12 & 1.88 & 6.44 \\
& $(1.19)$ & $(1.52)$ & $(2.56)$ \\
\hline
\end{tabular}

This table reports regressions corresponding to Fama and French (2002), table III. It regresses the k period ahead value weighted aggregate stock market return $R_{t, t+k}$ on the value weighted aggregate credit spread at time t, $C S_{t}$. T-statistics are in parentheses. The numbers are obtained by averaging the results from simulating the economy 1000 times over 57 years. The standard errors are corrected using Newey-West with 8 lags. 


\section{Table 8: Forecasting Return Volatility}

\begin{tabular}{|l||l|l|}
\hline$\sigma_{t+1}$ & Data & Model \\
\hline \hline$C S_{t}$ & $\begin{array}{l}5.65 \\
(8.29)\end{array}$ & $\begin{array}{l}3.12 \\
(4.39)\end{array}$ \\
\hline \hline$\sigma_{t+1}$ & Model & Data \\
\hline \hline$C S_{t}$ & 0.05 & 0.03 \\
$(0.02)$ & $(0.01)$ \\
\hline
\end{tabular}

This table reports regressions corresponding to Schwert (1989), tables VII and VIII. It regresses the one month ahead conditional volatility $\sigma_{t+1}$ of the value-weighted stock market return on i) the value weighted aggregate credit spread at time t, $C S_{t}$, and ii) on the value-weighted aggregate market leverage ratio in period $t, M L e v_{t}$. Standard errors are in parentheses. The numbers are obtained by averaging the results from simulating the economy 1000 times over 57 years. The standard errors are corrected using Newey-West with 8 lags. 